\title{
Familial dilated cardiomyopathy in the United Kingdom
}

\author{
P J Keeling, Y Gang, G Smith, H Seo, S E Bent, V Murday, A L P Caforio, \\ W J McKenna
}

Department of
Cardiological
Sciences, St George's
Hospital Medical
School, London
P J Keeling
Y Gang
G Smith
H Seo
S E Bent
A L P Caforio
W J McKenna
Department of
Medical Genetics,
St George's Hospital
Medical School,
London
V Murday
Institute of Clinical
Medicine,
Department of
Cardiology,
University of Padua,
Italy
A L P Caforio
Correspondence to:
Dr P Jeeling, Department
of Cardiological Sciences, St
George's Hospital Medical
School, Cranmer Terrace,
London SW 17 oRE.
Accepted for publication
30 November 1994.

Department of
Cardiological

Sciences, St George's

Hospital Medical

P J Keeling

Y Gang

S E Bent

W J McKenna

Department of

Tt George's Hospital

Medical School,

Institute of Clinical

Medicine,

Italy

Correspondence to:

Dr P J Keeling, Department Cardiological Sciences,

School, Cranmer Terrace,

Accepted for publication

30 November 1994

\begin{abstract}
Objectives-To determine the frequency and mode of inheritance of familial dilated cardiomyopathy in the United Kingdom.

Background-Two recent prospective studies have suggested that familial forms of dilated cardiomyopathy are common but have been limited by selective screening methods, inadequate diagnostic criteria, and low rates of ascertainment.
\end{abstract}

Methods-Prospective screening study of 236 relatives from 40 families of patients with dilated cardiomyopathy. Screening consisted of clinical examination, 12 lead electrocardiogram, and two-dimensional Doppler echocardiography. Relatives with systemic hypertension and other cardiac diseases were excluded from the study. All echocardiograms were performed by an experienced echocardiographer who was blinded to clinical information. Relatives were classified as having dilated cardiomyopathy, left ventricular enlargement (method of Henry), depressed fractional shortening, or as being normal. Relatives with abnormal investigations underwent further evaluation as appropriate.

Results-Twenty five cases of dilated cardiomyopathy were identified and came from $10(25 \%)$ of the 40 families screened. Pedigree analysis was most consistent with autosomal dominant inheritance and variable penetrance (65-95\%). Of the remaining apparently healthy relatives, $37(18 \%)$ were found to have left ventricular enlargement and nine (4\%) depressed fractional shortening; these values were significantly higher than those observed in 239 healthy controls $(24(10 \%), P=0.02$ and one $(0.4 \%), P=0.01$, respectively).

Conclusions-Patients with dilated cardiomyopathy commonly have an affected family member and a high proportion of apparently healthy relatives with minor echocardiographic abnormalities. Segregation analysis suggests that familial dilated cardiomyopathy is the result of the transmission of a rare autosomal dominant gene. Further studies are currently underway to characterise the molecular basis of familial dilated cardiomyopathy and identify early disease within these families.

(Br Heart f 1995;73:417-421)
Keywords: familial dilated cardiomyopathy, prospective screening study, idiopathic dilated cardiomyopathy

Over the years there have been several anecdotal reports of dilated cardiomyopathy in at least two members of the same family. ${ }^{1-6}$ These reports have not been able to assess the frequency of familial dilated cardiomyopathy because of their retrospective nature. Recently two large prospective studies from Italy and the Mayo Clinic $^{78}$ have shown that familial dilated cardiomyopathy is more common than previously suspected, occurring in $7-20 \%$ of patients with dilated cardiomyopathy. In both these studies, ${ }^{78}$ as in most other reports, ${ }^{236}$ pedigree analysis was most consistent with autosomal dominant inheritance. Other workers have, however, described families with autosomal recessive $^{14}$ and $\mathrm{X}$ linked inheritance. ${ }^{5}$

Although these prospective studies ${ }^{78}$ have highlighted the importance of genetic factors in dilated cardiomyopathy, they have been limited by selective screening methodology, ${ }^{7}$ inadequate diagnostic criteria, and incomplete ascertainment with many other relatives suspected of, but not confirmed as, having the condition. The aim of the present study was to assess the frequency and mode of inheritance of familial dilated cardiomyopathy in the United Kingdom by prospectively screening 236 relatives from 40 families of patients with dilated cardiomyopathy.

\section{Methods}

PATIENTS

The clinical diagnosis of dilated cardiomyopathy was made according to recommended criteria ${ }^{910}$ and all patients underwent cardiac catheterisation and right ventricular endomyocardial biopsy. Patients with features of myocarditis ${ }^{11}$ on endomyocardial histology were excluded from the study. Between November 1990 and March 199392 new cases of dilated cardiomyopathy were identified at our institution. All patients had a three to four generation pedigree constructed. Of these, a number were unable to provide the necessary details concerning the pedigree or contact data $(\mathrm{n}=$ nine $)$, had too small a living pedigree $(n=13)$, or doubtful parentage within the nuclear family ( $\mathrm{n}=$ eight). Screening was offered to the remaining 62 families irrespective of family history or the presence of suspected familial disease. Of these, 22 were unable or unwilling to undergo 
Table 1 Clinical characteristics of patients with dilated cardiomyopathy participating in family screening compared with those of a cohort of patients not involved in screening

\begin{tabular}{|c|c|c|c|}
\hline & Family screening & No family screening & $p$ Value \\
\hline \multirow{3}{*}{$\begin{array}{l}\text { No } \\
\text { Mean (SD) (range) age (years) } \\
\text { Sex (male) (\%) } \\
\text { New York Heart Association } \\
\text { functional class } \\
\text { Mean (SD) (range) duration (months) }\end{array}$} & \multirow[t]{2}{*}{$\begin{array}{l}40 \\
40(13)(12-63) \\
28(70)\end{array}$} & \multirow[t]{2}{*}{$\begin{array}{l}118 \\
42(13)(17-74) \\
89(75)\end{array}$} & $\begin{array}{l}\text { NS } \\
\text { NS }\end{array}$ \\
\hline & & & \\
\hline & I/II 38 III 2 & \multirow[t]{2}{*}{$\begin{array}{c}\text { I/II } 65 \text { III/IV } 53 \\
34(48)(0-204)\end{array}$} & $\begin{array}{l}0 \cdot 0001 \\
\text { NS }\end{array}$ \\
\hline \multirow{2}{*}{$\begin{array}{l}\text { No of patients with } \\
\text { mild hypertension (\%) } \\
\text { excess alcohol consumption (\%) }\end{array}$} & & & \\
\hline & $\begin{array}{l}5(13) \\
6(15)\end{array}$ & $\begin{array}{l}17(14) \\
27(23)\end{array}$ & $\begin{array}{l}\text { NS } \\
\text { NS }\end{array}$ \\
\hline \multicolumn{4}{|l|}{ Echocardiographic data } \\
\hline \multirow{8}{*}{$\begin{array}{l}\text { Mean (SD) LVEDD (mm) } \\
\text { Mean (SD) LVEDD\% } \\
\text { Mean (SD) LVESD (mm) } \\
\text { Mean (SD) FS (\%) } \\
\text { Left ventricular ejection fraction (\%) } \\
\text { Exercise capacity } \\
\text { Mean (SD) maximal } \mathrm{VO}_{2} \\
\text { (ml/kg/min) } \\
\text { Mean (SD) \% predicted maximal } \\
\mathrm{VO}_{2}\end{array}$} & $67(11)$ & $70(11)$ & NS \\
\hline & $139(25)$ & $145(27)$ & \\
\hline & $58(12)$ & $60(13)$ & NS \\
\hline & $14(6)$ & $14(8)$ & \\
\hline & $28(9)$ & 26 (11) & NS \\
\hline & & & \\
\hline & $24 \cdot 4(10 \cdot 6)$ & $19 \cdot 1(8 \cdot 7)$ & 0.03 \\
\hline & $68(24)$ & $51(23)$ & 0.005 \\
\hline
\end{tabular}

LVEDD, left ventricular end diastolic dimension; LVEDD\%, percentage predicted left ventricular end diastolic dimension; LVESD, left ventricular end systolic dimension; $\mathrm{FS}=$ fractional shortening; $\mathrm{VO}_{2}$, maximal oxygen consumption; NS, not significant.

screening at our institution and thus 40 families participated in prospective screening. Table 1 shows, the clinical features, echocardiographic measurements, left ventricular ejection fraction, and exercise capacity of these 40 patients. Patients with a history of mild premorbid systemic hypertension ( $\mathrm{n}=$ five) or excess alcohol consumption ( $\mathrm{n}=\mathrm{six}$ ) were included in the study but no patient developed dilated cardiomyopathy during the peripartum period.

\section{RELATIVES STUDIED}

Prospective screening of these 40 families resulted in 236 relatives (mean (SD) (range) age 34 (17) (4-87) years; 118 male) being assessed. Some 219 relatives were examined directly in the prospective study and the status of the remainder determined from examination of the relevant medical records or autopsy reports. One hundred and thirty three $(56 \%)$ were first degree relatives, 61 second degree, 36 third degree, and six fourth degree. Two generations were studied in 19 families, three generations in 19, and four generations in two. Most relatives $(200,91 \%)$ were symptomfree but 19 had at least one cardiac symptom (14 had mild exertional dyspnoea, 13 palpitation, four chest pain, and one syncope).

\section{SCREENING METHODOLOGY}

Screening consisted of a clinical examination with blood pressure measurement, 12 lead electrocardiogram, and two-dimensional Doppler echocardiography. Relatives with a history of mild systemic arterial hypertension were included but those with clinically important or documented systemic arterial hypertension during the physical examination were excluded from the study. Systemic hypertension was defined as a blood pressure measurement equal to or greater than $160 / 90$ $\mathrm{mm} \mathrm{Hg}$ on at least two distinct occasions. Relatives with a history of chronic excess. alcohol consumption (males more than eight units per day, females more than six units per day) were included in the study. Relatives were questioned about the amount of exercise performed and individuals who regularly
Figure 1 Outcome of screening 236 relatives of patients with dilated cardiomyopathy. performed in excess of $20 \mathrm{~min}$ moderate/ strenuous exercise on two or more occasions per week were recorded as being "athletic".

Echocardiograms were performed by a single experienced echocardiographer unaware of the family history and clinical data with high quality equipment (Hewlett Packard 77020A). Echocardiographic measurements of chamber and wall thickness were obtained at the level of the papillary muscle from two dimensional $M$ mode guided recordings in the short axis view. A second independent echocardiographer provided additional echocardiographic measurements from these recordings and ensured quality control. A third independent assessment of the recording was made in cases in which there was disagreement concerning the diagnosis or if the study was of insufficient quality when it was repeated. Normal values for left ventricular end diastolic cavity dimensions were calculated using a standard formula and corrected for age and body surface area. ${ }^{12}$ The following regression equation was used to calculate the predicted left ventricular end diastolic cavity dimension

Predicted left ventricular end diastolic diameter $=45.3(B S A) 1 / 3-0.03$ (age) -7.2

in which BSA is body surface area. Left ventricular enlargement was defined as a left ventricular end diastolic diameter greater than $112 \%$ predicted value and depressed fractional shortening as less than $25 \%$. These cutoff levels were confirmed in a separate study of 239 normal individuals using identical methodology. Relatives were classified according to these definitions as having (a) an echocardiogram compatible with dilated cardiomyopathy, (b) left ventricular enlargement, (c) depressed fractional shortening, or (d) of being normal. Relatives with suspected dilated cardiomyopathy underwent invasive evaluation with selective coronary arteriography if they were older than 40 years of age, had a history of chest pain, or there was electrocardiographic evidence of cardiac ischaemia on treadmill exercise testing. Relatives with mild echocardiographic abnormalities were assessed by maximal exercise testing and those with positive tests underwent cardiac catheterisation. Familial disease was considered to be present when at least one relative was affected by dilated cardiomyopathy. Screening was extended to involve all living relatives when an affected relative was identified, or to involve the next generation when a minor echocardiographic abnormality was detected. The medical records and post mortem findings of deceased relatives with suspected familial disease were reviewed to confirm or refute the diagnosis.

\section{STATISTICAL ANALYSIS}

Values are expressed as mean (SD). The student's $t$ test was used to compare quantitative data and the $\chi^{2}$ test or Fisher's exact test (with Yates's correction) was used to compare the relative frequency of characteristics in patients or relatives, or both, with and without disease. $P<0.05$ was considered significant. 
Table 2 Characteristics of index patients with familial and non-familial dilated cardiomyopathy

\begin{tabular}{|c|c|c|c|}
\hline & $\begin{array}{l}\text { Familial dilated } \\
\text { cardiomyopathy }\end{array}$ & $\begin{array}{l}\text { Non-familial } \\
\text { dilated cardiomyopathy }\end{array}$ & p Value \\
\hline $\begin{array}{l}\text { Mean (SD) age (years) } \\
\text { Mean (SD) sex (male) }\end{array}$ & $41(12)$ & $40(15)$ & NS \\
\hline \multicolumn{4}{|l|}{$\begin{array}{l}\text { New York Heart Association } \\
\text { functional class }\end{array}$} \\
\hline I & 7 & 23 & NS \\
\hline II & 1 & 7 & NS \\
\hline III & & & NS \\
\hline Mean (SD) duration (months) & $57(53)$ & $27(31)$ & 0.08 \\
\hline \multicolumn{4}{|l|}{ No of patients with } \\
\hline mild hypertension (\%) & $0(0)$ & $5(17)$ & NS \\
\hline \multicolumn{4}{|l|}{ Echocardiographic data } \\
\hline Mean (SD) LVEDD (mm) & $64(11)$ & $68(11)$ & NS \\
\hline Mean (SD) LVEDD\% & $128(13)$ & $142(27)$ & NS \\
\hline Mean (SD) LVESD (mm) & $53(11)$ & 59 (13) & NS \\
\hline Mean (SD) FS (\%) & $17(6)$ & $13(6)$ & NS \\
\hline Left ventricular ejection fraction (\%) & $30(10)$ & $27(9)$ & NS \\
\hline \multicolumn{4}{|l|}{ Echocardiographic data } \\
\hline $\begin{array}{l}\text { No of patients with interventricular } \\
\text { conduction block }(\%)\end{array}$ & $3(30)$ & $11(37)$ & NS \\
\hline No of patients with left bundle & $2(20)$ & $13(43)$ & NS \\
\hline $\begin{array}{l}\text { No of patients with third degree } \\
\text { atrioventicular block (\%) }\end{array}$ & $0(0)$ & $1(3)$ & NS \\
\hline \multicolumn{4}{|l|}{ Exercise capacity } \\
\hline \multirow{2}{*}{$\begin{array}{l}\mathrm{Mean}(\mathrm{SD}) \text { maximal } \mathrm{Vo}_{2} \\
(\mathrm{ml} / \mathrm{kg} / \mathrm{min}) \\
\mathrm{Mean}(\mathrm{SD}) \% \text { predicted maximal } \\
\mathrm{VO}_{2}\end{array}$} & $28 \cdot 1(6)$ & $23 \cdot 1(12)$ & NS \\
\hline & $83(18)$ & $64(24)$ & 0.04 \\
\hline
\end{tabular}

See table 1 for key to abbreviations.

Family A

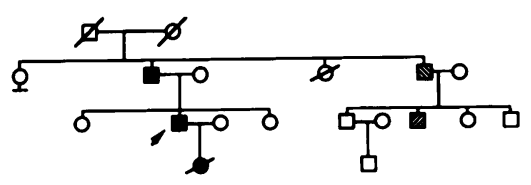

Family C
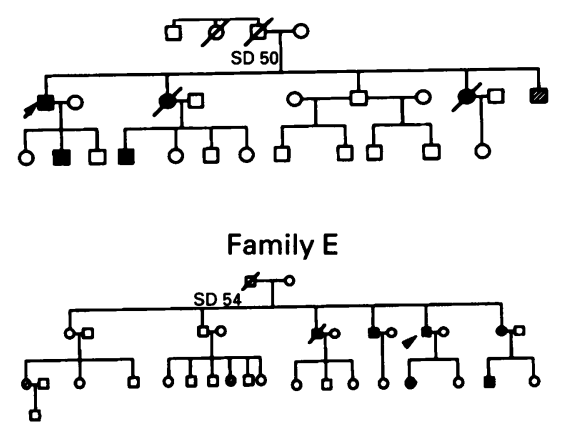

Family G
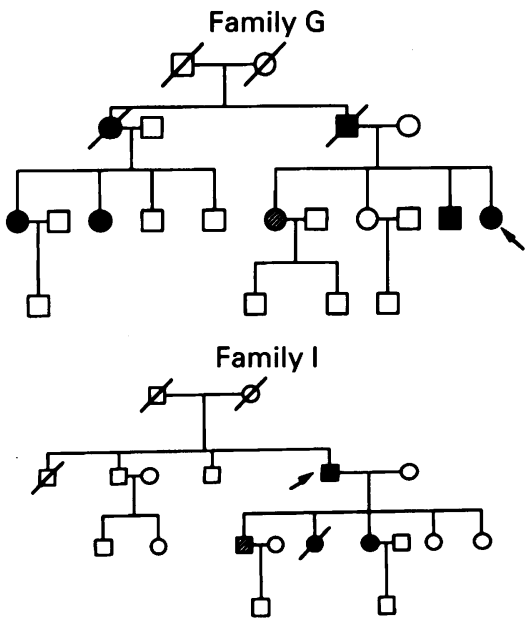

Affected
Left ventricular enlargement
Depressed fractional shorten $\square$ Unaffected

Figure 2 Pedigrees of the 10 families with documented familial dilated cardiomyopathy.
Results

PATIENTS PARTICIPATING IN FAMILY

SCREENING

Table 1 shows the characteristics of the 40 patients who participated in the prospective family screening. Comparative data of a cohort of 118 patients with dilated cardiomyopathy identified at this institution who were not subject to such screening are also given. Patients participating in prospective family screening were similar with respect to age, duration of symptoms, proportion of patients with mild systemic hypertension or excess alcohol consumption, echocardiographic measurements, and left ventricular ejection fraction, but were less limited according to New York Heart Association functional class and had a higher maximal oxygen consumption compared with the finding of patients not involved in screening (see table 1).

OUTCOME OF FAMILY SCREENING

Figure 1 shows the outcome of screening 236 relatives of patients with dilated cardiomyopathy. Twenty five relatives (11\%) with dilated cardiomyopathy were identified and the diagnosis was suspected in a further two but could not be confirmed as they refused to undergo cardiac catheterisation. Of the remaining relatives, 37 had left ventricular enlargement, nine depressed fractional shortening, and 160 normal screening investigations. Two additional relatives gave a history of exertional chest pain, had electrocardiographic evidence of exercise induced cardiac ischaemia, and documented obstructive coronary artery disease and one relative had echocardiographic evidence of hypertrophic cardiomyopathy.

\section{RELATIVES WITH FAMILIAL DILATED CARDIOMYOPATHY}

Dilated cardiomyopathy was documented in 25 relatives $(11 \%)$ (mean (SD) age (range) 35 (15) (4-65) years; 12 male, 22 first degree relatives). Affected relatives came from 10 families and represented $25 \%$ of those screened. Of the affected relatives, 12 had suffered a disease related death, five had undergone orthotopic heart transplantation for end stage dilated cardiomyopathy, but eight were undiagnosed and only identified through prospective screening. Relatives diagnosed by screening were mostly asymptomatic but three gave a history of mild palpitations for which they had not sought medical attention. Index patients with an affected relative were similar to those with sporadic dilated cardiomyopathy with regard to clinical features, echocardiographic measurements, electrocardiographic data, and left ventricular ejection fraction (table 2). Index patients with familial dilated cardiomyopathy, however, had been symptomatic for a longer period of time, had greater exercise capacity, and a trend towards less severe left ventricular dilatation or dysfunction than those with nonfamilial disease (table 2).

Figure 2 shows the pedigrees of the 10 
families with documented familial dilated cardiomyopathy. These families had between two and six affected members and involved multiple generations in all but one pedigree (family $\mathrm{J}$ ). In all pedigrees there was strong evidence in support of autosomal dominant inheritance. Assessment of disease penetrance revealed that penetrance was variable and incomplete (65-95\%) (for example see family E). Analysis of offspring risk in all 40 pedigrees indicated that the likelihood of an affected individual transmitting dilated cardiomyopathy to a child was approximately $20 \%$ (excluding index cases, relatives not screened and relatives less than 16 years of age).

\section{RELATIVES WITH MILD ECHOCARDIOGRAPHIC} ABNORMALITIES

Of the 208 apparently healthy relatives screened (excluding relatives with proven or suspected dilated cardiomyopathy, or hypertrophic cardiomyopathy), 37 (18\%) had left ventricular end diastolic dimensions above normal after correction for age and body size, and nine (4\%) had depressed left ventricular fractional shortening. The frequency of left ventricular enlargement and depressed fractional shortening was significantly higher in the relatives of patients with dilated cardiomyopathy (24 (10\%), P = 0.02) compared with that of a control population which comprised 239 healthy participants (one $(0.4 \%), P=0.01)$ assessed using the same methodology and diagnostic criteria.

\section{Discussion}

In this study we prospectively screened 236 relatives from 40 families of patients with dilated cardiomyopathy applying strict diagnostic criteria ${ }^{910}$ and achieving high levels of ascertainment. We have confirmed the recent report from the Mayo Clinic* that dilated cardiomyopathy is commonly familial and most consistent with autosomal dominant inheritance with incomplete penetrance. In addition, we have shown that a high proportion of apparently healthy relatives have left ventricular enlargement $(18 \%)$ or depressed fractional shortening (4\%). The relevance of this finding in relation to the presence of early dilated cardiomyopathy remains to be established.

In the present study screening was offered to families able to provide the necessary family information who were willing or able to undergo screening at our centre; however, families with small living pedigrees, missing important family members, or uncertain parentage were not offered screening. We recognise the potential for selection bias introduced by such an approach but these practical difficulties affect all family screening studies, particularly in cases involving rare conditions such as dilated cardiomyopathy, performed from a single centre. Despite this limitation it is important to emphasise that we like Michels et $a l^{8}$ but unlike others ${ }^{7}$ offered screening to families irrespective of the presence or absence of suspected familial disease. This is important given the observation that affected relatives are often asymptomatic and can be identified only through prospective screening; this is likely to explain the lower estimate of familial prevalence $(7 \%)$ from Italy. ${ }^{7}$ In the present study index patients who participated in screening were similar to those who did not and supports our belief that the families screened in the present study are mainly representative of families of patients with dilated cardiomyopathy. It is important, however, as with all prospective studies, to recognise the potential for referral bias. In our centre, as in all tertiary centres, patients with suspected familial dilated cardiomyopathy are more likely to be referred for assessment than patients considered at low risk of familial disease leading to an over-estimation of familial prevalence.

Dilated cardiomyopathy is multicausal and it is often not possible to accurately define the aetiology. Identification of individuals with familial dilated cardiomyopathy, which is probably genetic in aetiology, enabled us to determine whether "genetic" disease differed from that more likely to have an environment aetiology. Although patients with and without affected relatives were similar in most respects, those with familial disease had a longer symptomatic illness, better exercise capacity, and less marked left ventricular dilatation or dysfunction. Whether these observations reflect genuine differences in the clinical presentation and natural history between genetic and non-genetic dilated cardiomyopathy remains to be confirmed.

The identification of familial dilated cardiomyopathy has several important implications for the affected individual, their families, and the medical profession. Newly identified individuals with dilated cardiomyopathy benefit from the early introduction of angiotensin converting enzyme inhibitor treatment even when asymptomatic ${ }^{13}$ and should be closely monitored to identify and treat any complications which may arise. Furthermore, the identification of an affected relative within a family dramatically increases the likelihood of additional relatives being affected and makes screening the extended pedigree advisable and genetic counselling mandatory. Clearly, this is of great importance if screening programmes for familial dilated cardiomyopathy become more widely available. We believe that the findings in the present study should promote discussion on screening for familial dilated cardiomyopathy and provide practical guidelines by which this may be achieved and more effective genetic counselling for patients and their families.

Clearly, there are several practical difficulties in screening for familial dilated cardiomyopathy. First, our ability to distinguish between genetic and non-genetic disease (phenocopies) is limited and even within a family context different inheritance patterns have been observed (genetic heterogeneity). Second, dilated cardiomyopathy exhibits marked clinical and morphological heterogeneity and although most patients present 
with end stage heart failure some individuals (or families) are characterised by marked conduction disturbance ${ }^{14}{ }^{15}$ or mild ventricular dilatation. ${ }^{16}$ At present it is unclear whether these clinical entities are part of a wide spectrum of a single disease or represent several distinct but related conditions. Finally, screening children is particularly problematic because of the greater margins of error in small hearts which have not completed their growth $^{17}$ and because of the potential for disease manifestation in later life. ${ }^{18}$

Perhaps the greatest dilemma in screening for familial dilated cardiomyopathy, however, involves the identification of early disease. Current diagnostic criteria for dilated cardiomyopathy ${ }^{10}$ identifies patients with end stage disease but not those with early disease in which there may be less marked ventricular dilatation or dysfunction. It is thus interesting to speculate that the high prevalence of mild left ventricular enlargement in relatives of patients with dilated cardiomyopathy noted in this and other studies ${ }^{819}$ may represent early dilated cardiomyopathy. If this hypothesis is true and a significant proportion of these relatives do develop progressive left ventricular dilatation and clinical dilated cardiomyopathy it will be necessary to reassess our current estimates for familial prevalence and offspring risk. This possibility can be addressed only by the prospective follow up of relatives with minor echocardiographic abnormalities or the development of molecular diagnostic techniques.

In this study we have shown that patients with dilated cardiomyopathy commonly have a close family member similarly affected. Analysis of these families suggests that familial dilated cardiomyopathy is likely to be caused by the transmission of a rare autosomal dominant gene within the family. Although the molecular basis of familial dilated cardiomyopathy is currently unknown, linkage analysis promises to identify the gene(s) responsible and thereby improve our ability to identify not only affected individuals but also those with preclinical disease.

1 Emanuel $R$, Withers $R$, O'Brian $K$. Dominant and recessive modes of inheritance in idiopathic cardiomyopathy. Lancet 1971;13:1065-7.

2 Ross RS, Bulkley BH, Hutchins GM, et al. Idiopathic familial myocardiopathy in three generations: a clinical and pathological study. Am Heart f 1978;96:170.

3 Gardner RJ, Hanson JW, Ionasescu VV, et al. Dominantly inherited dilated cardiomyopathy. Am f Med Genet 1987;27:61-73.

4 Goldblatt J, Melmed J, Rose AG. Autosomal recessive inheritance of idiopathic dilated cardiomyopathy in a inheritance of idiopathic dilated cardiomyopathy in 249-54.

5 Berko BA, Swift M. X-linked dilated cardiomyopathy. N Engl f Med 1987;316:1186-91.

6 MacLennan BA, Tsoi EY, Maguire C, Adgey AA. Familial idiopathic congestive cardiomyopathy in three generations: a family study with eight affected members. $Q \mathcal{M}$ Med 1987;63:335-47.

7 Mestroni L, Miani D, Di Lenarda A, et al. Clinical and pathologic study of familial dilated cardiomyopathy. $A m \mathfrak{f}$ Cardiol 1990;65:1449-53.

8 Michels VV, Moll PP, Miller FA, et al. The frequency of familial dilated cardiomyopathy in a series of patients with idiopathic dilated cardiomyopathy. $N \mathrm{Eng} f \mathrm{Med}$ 1992;326:77-82.

9 Brandenberg RO, Chazov E, Cherian G, et al. Report of the WHO/ISFC task force on definition and classification of the cardiomyopathies. Circulation 1981;64: tion of

10 Manolio TA, Baughman KL, Rodeheffer $R$, et al. Prevalence and etiology of idiopathic dilated cardioPrevalence and etiology of idiopathic dilat

11 Aretz HT, Billingham ME, Edwards WD, et al. Myocarditis, a histopathologic definition and classification. carditis, a histopathologic definition

12 Henry WL, Gardin JM, Ware JH. Echocardiographic measurements in normal subjects from infancy to old age. Circulation 1980;62:1054-61.

13 The SOLVD investigators. Effect of enalapril on mortality and the development of heart failure in asymptomatic patients with reduced left ventricular ejection fractions. N Engl f Med 1992;327:685-91.

14 Graber HL, Unverferth DV, Baker PB, Ryan JM, Baba N, Wooley CF. Evolution of a hereditary cardiac conduction and muscle disorder: a study involving a family with six generations affected. Circulation 1986;74:21-35.

15 Schrader R, Kunkel B, Schneider M, Kaltenbach M. Two families with dilatative cardiomyopathy. Dtsch Med families with dilatative cardion

16 Karen A, Billingham ME, Weintraub D, Stinson EB Popp RL. Mildly diltated congestive cardiomyopathy. Circulation 1985;72:302-9.

17 Schmaltz AA, Apitz J, Hort W. Dilated cardiomyopathy in childhood: problems of diagnosis and long-term followup. Eur Heart $\mathcal{f} 1987 ; 8: 100-5$.

18 Pastores GM, Michels VV, Schaid DJ, et al. Search for the gene defect in familial idiopathic dilated cardiomyopathy. Cytogenet Cell Genet 1991;58:2102.

19 Zachara E, Caforio ALP, Carboni GP, et al. Familial aggregation of idiopathic dilated cardiomyopathy: clinical features and pedigree analysis in 14 families. $\mathrm{Br}$ Hear $\mathcal{f} 1993 ; 69: 129-35$. 